\title{
Evaluation of functional potentiality of selected commonly consumed foods of Bangladesh
}

\author{
Nazma Shaheen ${ }^{1}$, Avonti Basak Tukun ${ }^{1}$, Saiful Islam ${ }^{1}$, Nafis Md. Irfan ${ }^{1}$, Ishrat Nourin \\ Khan $^{1}$ and Towhid Hasan ${ }^{1}$
}

Institute of Nutrition and Food Science, University of Dhaka, Dhaka-1000, Bangladesh

Corresponding author: Nazma Shaheen, PhD, Professor, Institute of Nutrition and Food Science, University of Dhaka, Dhaka-1000, Bangladesh

Submission Date: July 20, 2016, Accepted Date: November 27, 2016, Publication Date: November 30, 2016

Citation: Shaheen N., Tukun A.B., Islam S., Irfan N.Md., Khan I.N., and Hasan T. Evaluation of functional potentiality of selected commonly consumed foods of Bangladesh. Functional Foods in Health and Disease 2016; 6(11):735-753

\begin{abstract}
Background: Rising tide of chronic nutrition related non-communicable diseases yoked with extant under nutrition problems makes it imperative to carry out scientific research towards the discovery of functional foods. Although the emergence of these diseases are believed to be related to a constellation of dietary, socio-economic and lifestyle related risk factors, central to the pathogenesis of these diseases (or disease states) are free radicals, oxidative stress, and inflammatory processes typically accompanied by pain. Therefore, functional whole foods with physiologically active antioxidants, anti-inflammatory, and analgesic compounds seem to be the most promising option to deal with the pathogenesis of existing and emerging chronic diseases burden of Bangladesh.
\end{abstract}

Methods: Edible portions of 70 commonly consumed Bangladeshi foods - including one cereal, five legumes, fourteen vegetables, four tea varieties, five oil seeds, twenty spices, and twenty one fruits - were evaluated for total phenol content (TPC) by Folin-Ciocalteau assay. To evaluate functional potentiality, in vitro antioxidant capacity $(\mathrm{AC})$ of selected food items were evaluated by DPPH (2,2-diphenyl-1-picrylhydrazyl) radical scavenging assays, in vitro anti-inflammatory potential by observing the production of pro-inflammatory cytokine TNF- $\alpha$ using J774A.1 cells stimulated with lipopolysaccharide (LPS), in vivo anti-inflammatory potential by measuring carrageenan induced rat paw edema reduction, and in vivo analgesic potential by acetic acid induced writhing test in mice.

Results: Spices, oilseeds, and teas showed high concentration of TPC among the analyzed foods, while spices and teas exhibited notable AC. Green tea showed highest concentrations of TPC 
(2349 mg Gallic Acid Equivalent / g) and AC (2432 $\mu$ mole Trolox Equivalent/g). Fourteen food items showed potential in vitro anti-inflammatory activity with confirmatory dose response effect shown by 8 items. In vivo, black sesame and yellow mustard expressed anti-inflammatory and analgesic effects in a dose dependent manner.

Conclusion: This study found commonly consumed food items representing different food groups of Bangladesh to contain diverse range of polyphenols and antioxidant capacities. Out of the tested food items, black sesame and yellow mustard both demonstrated anti-inflammatory and analgesic potential in the animal model. The findings of this study can be used to promote polyphenols rich foods through dietary guidelines and facilitate epidemiological research investigating diet-disease relationships.

Key words: Polyphenols, Total phenol content, Antioxidant capacity, Anti-inflammatory activity, Analgesic activity, Functional foods

\section{BACKGROUND}

Bangladesh is facing an epidemiological spectrum of pervasive under nutrition at one end [1-3] and a rising tide of non-communicable diseases (NCDs) yoked with associated risk factors on the other end, contributing to the country's health-care cost [4-5] and mortality rate [6]. Oftentimes this collision of food insecurity and under nutrition and nutrition-related non-communicable diseases (NRNCDs) is occurring within the same population and, in many settings, in the same individuals [7]. Therefore, it is imperative to adopt a holistic approach of 'optimal nutrition' on a national level, rather than supplying diets which merely provide nutrients to meet particular organic needs. To this end, scientific research for finding 'functional foods'- foods that in addition to providing the body with basic macro and micronutrients, supply it with bioactive ingredients with the potential to decrease NRNCDs and promote physical and mental well-being - is receiving renewed interest [8].

Although the emergence of NRNCDs are believed to be related to a constellation of dietary, socio-economic and lifestyle related risk factors, central to the pathogenesis of these diseases (or disease states) are inflammatory processes which are typically accompanied by pain. Other hallmarks of inflammation include redness, swelling, heat, and loss of function of the affected area or areas, which involve interactions among many cell types and the production of - and responses to - a number of chemical mediators [9]. Self-limiting and rapidly resolved inflammatory reactions are essential for the body to remain healthy and maintain homeostasis against infections and tissue injury. However, chronic inflammatory processes like atherogenesis contribute to the perpetuation and progression of several disorders through a variety of mechanisms [9]. These inflammatory processes induce oxidative stress and reduce cellular antioxidant capacity to mediate an initiating role in the pathogenesis of most common conditions of chronic diseases, including insulin resistance, beta cell dysfunction, impaired glucose tolerance, diabetes mellitus, endothelial dysfunction, osteoarthritis, cardiovascular disease, Alzheimer's disease, Parkinsons' disease, cancer, and aging [10-11]. One promising avenue to cope with oxidative stress and deal with inflammatory insults is to supply the body with antioxidants and anti-inflammatory agents. However, supporting evidence for the application of 
supplements - either synthetic or those extracted from natural foods - of antioxidants, antiinflammatory, and analgesic compounds is still ambiguous [12-14]. Nevertheless, the protective role of antioxidant rich whole foods in the diet against the risk of cardiovascular diseases and cancer are also corroborated by several epidemiologic findings [15-16]. This is most likely because these bioactive compounds, when chemically synthesized or separated from foods, not necessarily exert the identical effects compared to their natural existence within the food matrix. Therefore, functional whole foods with physiologically active antioxidants, anti-inflammatory, and analgesic compounds appear to be the most promising option when it comes to dealing with the pathogenesis of existing and emerging chronic diseases which are currently burdening Bangladesh.

Despite the potential role that functional foods might play against the rising tide of chronic diseases, there is a paucity of information on the bioactive ingredients of commonly consumed Bangladeshi foods. Although some sporadic studies have been carried out in the field of food functionality, these are either focused on traditional medicinal plants [17-18] or limited to determining only the content and one free radical scavenging activity of a particular class of bioactive compounds (e.g. polyphenols), let alone evaluating their potentiality in vivo [19-21]. In this study, commonly consumed Bangladeshi foods representing different food groups have been screened for their functionality based on their contents of bioactive compounds and demonstrated beneficial role against oxidative stress and inflammatory processes, including the pain. In light of the increasing attention polyphenolic compounds are gaining for their noticeable antioxidant property, this article reports total polyphenols content of 70 food items determined employing modified Folin-Ciocalteau method. This paper also presents the functional potential of selected food items as screened by monitoring the 2,2-diphenyl-1-picrylhydrazyl radical scavenging activity (antioxidant potential), observing the influence of DMSO extracts of these foods on the production of pro-inflammatory cytokine TNF- $\alpha$ using J774A.1 cells stimulated with lipopolysaccharide (LPS) to mimic inflammatory status in cell model (in vitro anti-inflammatory potential), assessing the capacity of these foods' DMSO extracts of inhibiting edema induced by injecting the edematogenic agent carrageenan into the subplantar region of the right hind paw of rats to mimic inflammatory status in animal model (in vivo anti-inflammatory potential), and observing the power of these food extracts in reducing the number of writhes induced by injecting acetic acid in rats (in vivo analgesic potential).

\section{METHODS AND MATERIAL}

\section{Chemicals and reagents}

\section{Sample extraction}

(i) Acetic acid (MERCK, Germany), (ii) acetone (MERCK, Germany), (iii) dichloromethane (MERCK, Germany), (iv) Dimethyl sulfoxide (DMSO) (Sigma Aldrich, Poland), and (v) nHexane (MERCK, Germany).

$T P C$

(i) Folin-Ciocalteau reagent (FCR) (MERCK, Germany), (ii) gallic acid (TIC, Japan), and (iii) sodium carbonate (Merck, Germany).

In vitro $A C$ 
(i) 2-(N-morpholino) ethanesulfonic acid buffer (DojinDo), (ii) 2, 2-diphenyl-1picrylhydrazyl radical (DPPH) (Wako, Japan), (iii) Trolox (6-hydroxy-2,5,7,8tetramethylchromane-2-carboxylic acid, a vitamin E analogue) (ALDRICH, Denmark), and (iv) ethanol (MERCK, Germany).

In vitro anti-inflammatory activity

(i) Dulbecco's Modified Eagles Medium (DMEM) (SIGMA, UK), (ii) 1\% penicillinstreptomycin solution Hybri-Max (SIGMA, UK), (iii) Fetal Calf Serum (FCS): $10 \%$ (v/v)/DMEM, (iv) Tryan Blue (0.4\% solution) (GIBCO\# 15250-061), (v) Dulbecco Phosphate Buffer Saline (PBS) (-): Ca, Mg free (SIGMA, UK), (vi) Hanks (-) Balanced salt solution (SIGMA \# 6648, UK), (v) Lipopolysaccharide (LPS): E. Coli (GIBCO), and (vi) mouse TNF- $\alpha$ Elisa Ready-SET-Go (e-Bioscience, USA).

In vivo anti-inflammatory and analgesic activity

(i) Acetic acid (Merck, Germany), (ii) carrageenan (Sigma-Aldrich, Germany), diclofenac sodium (Square Pharmaceuticals Ltd; Dhaka, Bangladesh), and (iii) normal saline $(0.9 \% \mathrm{NaCl})$ (Square Pharmaceuticals Ltd; Dhaka, Bangladesh).

\section{Plant materials}

Cereals: Porso millet (Panicum miliaceum)

Fruits: Emblic (Embilica officinalis), Banana (Musa paradisiaca), Burmese grape (Baccaurea ramiflora), Carambola (Averrhoa carambola), Elephant apple (Limonia acidissima), Guava (Psidium guajava), Hog plum (Spondias mombin), Honeydew melon (Cucumis melo), Jackfruit (Artocarpus heterophyllus), Jambolan (Syzygium cumini), Jambos (Syzygium jambos), Java apple (Syzygium samarangense), Karonda (Carissa carandas), Lakuch (Artocarpus lakoocha), Lychee (Litchi chinensis), Mango (Mangifera indica), Palmyra palm (Borassus flabellifer), Papaya (Carica papaya), Pineapple (Ananas comosus), Sapota (Manilkara zapota), and Watermelon (Citrullus vulgaris)

Oil seeds: Linseed (Linum usitatissimum), Red mustard (Bassica nigra), Yellow mustard (Bassica alba), Black sesame (Sesamum indicum), and Brown sesame (Sesamum indicum)

Pulses: Black gram (Vigna mungo), Green gram (Vigna radiata), Grass pea (Lathyrus sativus), Lentil (Lens culinaris), and Bengal gram (Cicer arietinum)

Vegetables: Bean (Phaseolus coccineus), Bitter gourd (Momordica charantia), Bottle Gourd (Lagenaria siceraria), Brinjal (Solanum melongena), Cabbage (Brassica oleracea), Carrot (Daucus carota), Cucumber (Cucumis sativus), Green chilli (Capsicum annuum), Ladies Finger (Abelmoschus esculentus), Onion (Allium cepa), Radish (Raphanus sativus), Spinach (Spinacia oleracea), Pumpkin (Cucurbita maxima), and Tomato (Lycopersicon esculentum)

Spices: Ajwain (Trachyspermum ammi), Bay leaf (Laurus nobilis), Black cardamom (Amomum subulatum), Black pepper (Piper nigrum), Green cardamom (Elettaria cardamomum), Cinnamon (Cinnamomum verum), Cloves (Syzygium aromaticum), Coriander leaves (Coriandrum sativum), Cumin seeds (Cuminum cyminum), Fenugreek (Trigonella foenum-graecum), Garlic (Allium 
sativum), Ginger root (Zingiber officinale), Red chilli (Capsicum annuum), Nigella seeds (Nigella sativa), Mace (Myristica fragrans), Sweet fennel (Foeniculum vulgare), Nutmeg (Myristica fragrans), Radhuni (Trachyspermum roxburghianum), Turmeric (Curcuma domestica), and White pepper (Piper nigrum)

Tea: Green tea (Camellia sinensis), Tea (BT-2) (Camellia sinensis), Tea (Mirzapur) (Camellia sinensis), and Organic tea (Camellia sinensis)

\section{Cell and culture}

The J774.1 mouse macrophage cells line were used for in vitro anti-inflammatory analysis and collected from Japanese Collection of Research Bioresources (JCRB). The J774A.1 cells were maintained in 10\% FCS containing Dulbecco's Modified Eagle's Medium (DMEM) supplemented with $100 \mathrm{U} / \mathrm{mL}$ penicillin and $100 \mu \mathrm{g} / \mathrm{mL}$ streptomycin. The cells were maintained at $37{ }^{\circ} \mathrm{C}$ in an atmosphere of $5 \% \mathrm{CO}_{2}$ and $95 \%$ air.

\section{Experimental animals}

Swiss albino mice (5-6 weeks old, 20-30 g) and Long-Evans rats (7-8 weeks old, 100-130 g) of either sex were used for in vivo experiments. They were purchased from the Animal Research Branch of the International Centre for Diarrhoeal Diseases and Research, Bangladesh (ICDDR, B) and fed with standard rat food obtained from same organization and water ad libitum. To acclimatize the animals to laboratory condition, they were kept in polyvinyl cage under the standard environmental condition of room temperature $23^{\circ} \pm 2^{\circ} \mathrm{C}, 55-10 \%$ relative humidity and 12-h light/dark cycle for 7 days. The animals were fasted overnight to maintain the hydration rate constant before the experiment. Ethical Review Committee, Faculty of Biological Science, University of Dhaka approved the research protocol to conduct this study involving experimental animals.

\section{Sample collection and preparation}

Functional potentiality of 70 commonly consumed foods comprising cereals, fruits, oil seeds, pulses, spices, tea and vegetables have been evaluated from 2008 to 2015. Samples were collected from local markets and transported in poly-bags to prevent moisture loss to the Food analysis laboratory of Institute of Nutrition and Food sciences (INFS), University of Dhaka. After collection and transportation, samples were washed under running water followed by distilled water and then air-dried on kitchen towels to remove the surface water. Homogenization of samples is essential for maximum extraction of the phenolic compounds; consequently, edible portion of the samples, either freeze dried or oven dried based on their nature, were pulverized. Highly perishable samples of fruits and vegetables were freeze-dried, while comparatively drier samples of cereals, oil seeds, pulses, and spices were oven-dried for pulverization. Ground samples were then packed in air-tight packet and stored at $-20^{\circ} \mathrm{C}$ prior to extraction and subsequent analysis.

\section{Sample extraction}

Total phenol content and anti-oxidant capacity (RSA) 
Ground samples $(1 \mathrm{~g})$ were sequentially extracted using $25 \mathrm{ml}$ of each hexane:dichloromethane (1:1) and acetone:water:acetic acid (AWA) (70:29.5:0.5). Hydrophilic AWA extract was separated after centrifugation at $2500 \mathrm{rpm}$ for 15 minutes, volume made up to $25 \mathrm{ml}$, and stored at $-20^{\circ} \mathrm{C}$ for triplicate estimation of total phenol content (TPC) and antioxidant capacity (AC).

\section{Anti-inflammatory and analgesic activity}

To estimate in vitro anti-inflammatory activity, $0.2 \mathrm{~g}$ samples were mixed with $5 \mathrm{ml}$ of DMSO. The mixture of sample and DMSO was stirred in a shaker at $130 \mathrm{rpm}$ over night at room temperature and centrifuged at $3000 \mathrm{rpm}$ for 5 minutes. After centrifugation, the supernatant collected as DMSO extraction was transferred by pipetting and $500 \mu 1$ of aliquots were stored at $25{ }^{\circ} \mathrm{C}$ for in vitro cell analysis. The sample extraction procedure for in vivo assessment was similar to the in vitro one, except for the concentration of DMSO solution and the amount of sample extracted. Twenty grams of samples were extracted by $100 \mathrm{ml}$ 1:1 DMSO and deionized water (DMSOW).

\section{Assessment of functional potentiality}

\section{Determination of TPC}

TPC of the AWA sample extracts was estimated colorimetrically according to Folin-Ciocalteau method [22]. For quantification of TPC, the standard curve was constructed using gallic acid solution of varying concentration. The concentrations of gallic acid solution were plotted on abscissa and the corresponding absorbance at $750 \mathrm{~nm}$ on ordinates. The TPC of the samples were calculated by extrapolation and expressed as gallic acid equivalent per gram of edible portion (mg GAE/g EP).

\section{Estimation of in vitro AC}

DPPH radical scavenging assay (DPPH-RSA) of Brand-Williams [23] was used for the estimation of in vitro AC of AWA sample extracts. Unlike TPC, DPPH-RSA was estimated by kinetics; hence, the absorbance of different volumes $(200,400$, and $800 \mu \mathrm{L})$ of $50 \%$ diluted sample at $520 \mathrm{~nm}$ was plotted along with the standard curve of Trolox solution [24]. The ratio of the sample extract and the standard curve was calculated to estimate the AC of assayed sample in terms of Trolox equivalent (TEAC) and expressed per gram of EP.

\section{In vitro anti-inflammatory activity}

In vitro anti-inflammatory activity was assessed by Herath [25]. The mouse macrophage (J774A cell) suspension with a concentration of $5.0 \times 105$ cells/well was seeded into each well of 96wells plates and incubated overnight at $37^{\circ} \mathrm{C}$ in an atmosphere of $5 \% \mathrm{CO}_{2}$ and $95 \%$ air which was followed by removal of cultured medium by washing with Hank's solution. After removal of cultured medium, $160 \mu \mathrm{l}$ DMEM with $20 \mu \mathrm{l}$ of LPS (1.0 $\mu \mathrm{g} / \mathrm{ml})$ (LPS plus) were added to 48 wells (LPS minus) and $180 \mu 1$ DMEM with $20 \mu \mathrm{l}$ of diluted sample extracts $(40 \mu \mathrm{g} / \mathrm{ml})$ to rest of the 96 well which were treated as control. The culture plate was incubated for 4 hours, and the supernatant was then collected and assayed for TNF- $\alpha$ content using the mouse TNF- $\alpha$ enzymelinked immunosorbant assay kit (Ready-Set-Go, eBioscience, USA). After this preliminary screening, samples extracts with at least $75 \%$ inhibition activity were assessed for dose response. 
Unlike preliminary assessment, dose response of the samples was carried out using different concentration of samples extracts; stored sample extracts were diluted by phosphate buffer saline (PBS) to get final concentration of $1,3,10$, and $40 \mu \mathrm{g} / \mathrm{ml}$ prior to the assessment.

In vivo anti-inflammatory activity

DMSOW extracts of four samples of black sesame, yellow mustard, green gram, and lentil were evaluated for anti-inflammatory activity by using carrageenan-induced rat's paw edema model [26-27]. Long-Evans adult rats were weighed and randomly divided into 10 groups, consisting of 6 rats in each, received doses of test samples and controls prior to carrageenan injection accordingly. Group 1 was kept as control giving normal saline (10 ml $/ \mathrm{kg}$, p.o.), while Group 2 was standard, receiving diclofenac sodium at the dose of $50 \mathrm{mg} / \mathrm{kg}$ body weight p.o. as reference standard. The rest of the groups were given two different doses of sample extracts, 200 and 100 $\mathrm{mg} / \mathrm{kg}$ body weight p.o. Half an hour after the oral administration of the various agents, acute inflammation was produced by injecting freshly prepared $1 \%$ carrageenan into sub-plantar region of the right hind paw of each animal. The volume of paw edema was measured plythesmometrically at 0 (before carrageenan injection), and 1,2, 3, and 4 hours after administration of carrageenan. The anti-inflammatory activity, expressed as percent inhibition of paw edema, was calculated using the formula: \% Inhibition $=[(\mathrm{Vc}-\mathrm{Vt}) / \mathrm{Vc}] \times 100$; where $\mathrm{Vc}$ and $\mathrm{Vt}$ represent average paw volume of control and treated animal respectively.

\section{In vivo analgesic activity}

The peripheral analgesic activity of the same four samples was evaluated using the acetic acid induced writhing method [28-31] in Swiss albino mice. The design of the assessment in terms of deploying mice in ten groups, the doses of sample extracts, reference drug and control, and administration of the agents were kept identical to the anti-inflammatory experiment. To create the sensation of pain, $0.6 \%$ acetic acid was administered intraperitoneally to the experimental animals after 30 minutes of oral ingestion of test samples. Each mouse was isolated in an individual chamber and observed to record the number of writhes (contractions of the abdominal muscles and stretching of hind limbs) they made in 10 minutes commencing 10 minutes after intraperitoneal administration of acetic acid solution. The number of writhes in each treated group was compared to that of a control group to determine the analgesia, which was calculated as: $\%$ inhibition of writhing $=[(\mathrm{Wc}-\mathrm{Wt}) / \mathrm{Wc}] \times 100$; where $\mathrm{Wc}$ is the average number of writhing reflex in the control group and $\mathrm{Wt}$ is the average number of writhing in the test groups.

\section{RESULTS and DISCUSSION}

\section{Screening for functionality/ functional potentiality: TPC and AC-RSA}

Seventy Bangladeshi foods, selected for evaluation of functional potentiality, represented seven different food groups. The amount of phenolic compounds estimated is denoted as "total phenol content" which includes any secondary natural metabolites arising biogenetically from either the shikimate/phenylpropanoid pathway or "polyketide "acetate/malonate pathway, or both in plants and commonly known as "plant phenolics" and "polyphenol" [32]. The present study found (Table 1) large variation of TPC among the analyzed foods; even among some food groups, particularly in fruits and teas. The lowest and highest TPC vary in fruits about $158 \mathrm{mg} \mathrm{GAE} / \mathrm{g}$ 
edible portion, whereas teas were discovered to have about $1292 \mathrm{mg}$ GAE. On the other hand, the pulse group exhibited little variation, varies only about $8 \mathrm{mg}$ of GAE per gram of fresh sample within the group. The variations in TPC are also implicit from the percent distribution; the 25th, 50th, and 75th percentiles were 0.51, 2.46, and $13.79 \mathrm{mg}$ of GAE/g EP respectively. As mentioned earlier, amid the analyzed foods TPC of fruits varied greatly which was found as low as $0.01 \mathrm{mg}$ to as high as $157.86 \mathrm{mg}$ of GAE with only 2 (emblic and wood apple) above the 75th percentile. The TPC of the vegetable groups varied from 0.6 to $13.91 \mathrm{mg}$ of GAE/g EP of which purple colored brinjal contained highest amount of phenolics. Contrary to fruits and vegetables, all of the analyzed teas and oilseeds were found to possess phenolic compounds in high amounts. The maximum number of foods fell above 75th percentile, apart from the tea and oilseeds, belonged to spices (cinnamon, cloves, radhuni, and sweet fennels).

Table 1: Total phenol content (TPC) and antioxidant capacity (AC) of commonly consumed foods of Bangladesh

\begin{tabular}{|c|c|c|c|c|}
\hline $\begin{array}{l}\text { Food } \\
\text { group }\end{array}$ & Food name & Scientific name & $\begin{array}{ll}\text { TPC } & \text { (mg } \\
\text { GAE/g) } & \end{array}$ & $\mathrm{AC}(\mu \mathrm{mol} \mathrm{TE} / \mathrm{g})$ \\
\hline \multicolumn{5}{|c|}{ Vegetables } \\
\hline 1 & Tomato & Lycopersicon esculentum & $1.49 \pm 0.1$ & $71.86 \pm 1.1$ \\
\hline 2 & Radish & Raphanus sativus & $0.60 \pm 0.0$ & $25.22 \pm 3.1$ \\
\hline 3 & Carrot & Daucus carota & $1.09 \pm 0.0$ & $70.57 \pm 9.5$ \\
\hline 4 & Cucumber & Cucumis sativus & $0.79 \pm 0.0$ & $39.04 \pm 8.3$ \\
\hline 5 & Brinjal & Solanum melongena & $13.91 \pm 1.2$ & ND \\
\hline 6 & Pumpkin & Cucurbita maxima & $0.83 \pm 0.1$ & ND \\
\hline 7 & Cabbage & Brassica oleracea & $1.42 \pm 0.1$ & $0.75 \pm 0.1$ \\
\hline 8 & Bottle Gourd & Lagenaria siceraria & $0.56 \pm 0.0$ & $24.35 \pm 1.4$ \\
\hline 9 & Green chilli & Capsicum annuum & $3.59 \pm 0.8$ & $1.94 \pm 0.4$ \\
\hline 10 & Bean & Phaseolus coccineus & $3.06 \pm 0.8$ & $20.11 \pm 1.3$ \\
\hline 11 & Bitter gourd & Momordica charantia & $0.91 \pm 0.0$ & ND \\
\hline 12 & Ladies Finger & Abelmoschus esculentus & $5.75 \pm 1.3$ & $48.10 \pm 12.7$ \\
\hline 13 & Onion & Allium cepa & $2.41 \pm 0.7$ & $1.99 \pm 0.3$ \\
\hline 14 & Spinach & Spinacia oleracea & $3.93 \pm 1.0$ & ND \\
\hline \multicolumn{3}{|c|}{ Number of sample above $75^{\text {th }}$ quartile } & 2 & 1 \\
\hline \multicolumn{3}{|c|}{ Range } & $0.56-13.91$ & $0.75-71.86$ \\
\hline \multicolumn{5}{|l|}{ Fruits } \\
\hline 1 & Papaya & Carica papaya & $1.38 \pm 0.1$ & ND \\
\hline 2 & Banana & Musa paradisiaca & $6.13 \pm 1.1$ & $19.11 \pm 1.8$ \\
\hline 3 & Guava & Psidium guajava & $13.75 \pm 1.2$ & $12.17 \pm 1.4$ \\
\hline 4 & Elephant apple & Limonia acidissima & $18.97 \pm 1.6$ & $20.70 \pm 1.0$ \\
\hline 5 & Watermelon & Citrullus vulgaris & $0.21 \pm 0.0$ & $0.21 \pm 0.0$ \\
\hline 6 & Emblic & Embilica officinalis & $157.86 \pm 2.8$ & $185.78 \pm 3.5$ \\
\hline 7 & Jackfruit & Artocarpus heterophyllus & $0.03 \pm 0.0$ & $0.82 \pm 0.0$ \\
\hline 8 & Mango & Mangifera indica & $0.03 \pm 0.0$ & $0.43 \pm 0.0$ \\
\hline 9 & Lychee & Litchi chinensis & $0.10 \pm 0.0$ & $0.24 \pm 0.0$ \\
\hline 10 & Jambolan & Syzygium cumini & $0.05 \pm 0.0$ & $0.25 \pm 0.0$ \\
\hline 11 & Burmese grape & Baccaurea ramiflora & $0.01 \pm 0.0$ & $0.11 \pm 0.0$ \\
\hline 12 & Carambola & Averrhoa carambola & $0.05 \pm 0.0$ & $1.53 \pm 0.4$ \\
\hline 13 & Hog plum & Spondias mombin & $0.03 \pm 0.1$ & $0.44 \pm 0.1$ \\
\hline
\end{tabular}




\begin{tabular}{|c|c|c|c|c|}
\hline 14 & Honeydew melon & Cucumis melo & $0.03 \pm 0.0$ & $0.33 \pm 0.0$ \\
\hline 15 & Karonda & Carissa carandas & $0.10 \pm 0.0$ & $4.88 \pm 0.0$ \\
\hline 16 & Lakuch & Artocarpus lakoocha & $0.03 \pm 0.0$ & $0.8 \pm 0.1$ \\
\hline 17 & Palmyra palm & Borassus flabellifer & $0.03 \pm 0.0$ & $0.3 \pm 0.0$ \\
\hline 18 & Pineapple & Ananas comosus & $0.03 \pm 0.0$ & $0.21 \pm 0.2$ \\
\hline 19 & Java apple & Syzygium samarangense & $0.60 \pm 0.0$ & $1.53 \pm 0.3$ \\
\hline 20 & Sapota & Manilkara zapota & $0.01 \pm 0.0$ & $0.71 \pm 0.1$ \\
\hline 21 & Jambos & Syzygium jambos & $0.01 \pm 0.0$ & $0.2 \pm 0.7$ \\
\hline \multicolumn{3}{|c|}{ Number of sample above $75^{\text {th }}$ quartile } & 1 & 3 \\
\hline \multicolumn{3}{|c|}{ Range } & $0.01-157.9$ & $0.11-185.8$ \\
\hline \multicolumn{5}{|l|}{ Tea* } \\
\hline 1 & Green Tea & Camellia sinensis & $2348.60 \pm 69.9$ & $2432.8 \pm 110.0$ \\
\hline 2 & Organic tea & Camellia sinensis & $1271.10 \pm 24.3$ & $1532.6 \pm 82.9$ \\
\hline 3 & Tea (BT-2) & Camellia sinensis & $1501.70 \pm 79.9$ & $1376.7 \pm 66.9$ \\
\hline 4 & Tea (Mirzapur) & Camellia sinensis & $1056.74 \pm 34.8$ & $1269.9 \pm 38.6$ \\
\hline \multicolumn{3}{|c|}{ Number of sample above $75^{\text {th }}$ quartile } & 4 & 4 \\
\hline \multicolumn{3}{|c|}{ Range } & $1056.7-2348.6$ & $1269.9-2432.8$ \\
\hline \multicolumn{5}{|c|}{ Spices* } \\
\hline 1 & Radhuni & Trachyspermum roxburghianum & $18.11 \pm 1.2$ & $59.92 \pm 7.9$ \\
\hline 2 & Sweet fennel & Foeniculum vulgare & $32.16 \pm 2.1$ & $61.82 \pm 0.2$ \\
\hline 3 & Red chill & Capsicum annuum & ND & $45.17 \pm 3.6$ \\
\hline 4 & Coriander leaves & Coriandrum sativum & ND & $39.08 \pm 2.5$ \\
\hline 5 & Turmeric & Curcuma domestica & ND & $44.92 \pm 2.2$ \\
\hline 6 & Nigella seed & Nigella sativa & ND & $14.75 \pm 0.3$ \\
\hline 7 & Cloves & Syzygium aromaticum & $49.89 \pm 0.4$ & $179.21 \pm 15.5$ \\
\hline 8 & Cinnamon & Cinnamoтum verum & $21.02 \pm 0.5$ & $20.23 \pm 1.4$ \\
\hline 9 & Bay leaf & Laurus nobilis & $8.71 \pm 0.7$ & $11.68 \pm 0.0$ \\
\hline 10 & Ajwain & Trachyspermum ammi & $4.09 \pm 0.2$ & $10.92 \pm 0.0$ \\
\hline 11 & Ginger root & Zingiber officinale & $2.97 \pm 0.1$ & $6.47 \pm 0.7$ \\
\hline 12 & Nutmeg & Myristica fragrans & $2.96 \pm 0.2$ & $2.45 \pm 0.0$ \\
\hline 13 & Mace & Myristica fragrans & $2.51 \pm 0.2$ & $2.32 \pm 0.1$ \\
\hline 14 & Cumin seeds & Cuminum cyminum & $2.09 \pm 0.1$ & $2.29 \pm 0.1$ \\
\hline 15 & Black pepper & Piper nigrum & $1.50 \pm 0.0$ & $2.18 \pm 0.7$ \\
\hline 16 & Black Cardamom & Amomum subulatum & $1.13 \pm 0.0$ & $1.88 \pm 0.1$ \\
\hline 17 & Fenugreek & Trigonella foenum-graecum & $0.78 \pm 0.0$ & $1.74 \pm 0.1$ \\
\hline 18 & White pepper & Piper nigrum & $0.71 \pm 0.1$ & $1.17 \pm 0.0$ \\
\hline 19 & Green Cardamom & Elettaria cardamomum & $0.55 \pm 0.0$ & $1.05 \pm 0.0$ \\
\hline 20 & Garlic & Allium sativum & $0.39 \pm 0.03$ & $0.78 \pm 0.0$ \\
\hline \multicolumn{3}{|c|}{ Number of sample above $75^{\text {th }}$ quartile } & 4 & 6 \\
\hline \multicolumn{3}{|c|}{ Range } & $0.39-49.89$ & $0.78-179.21$ \\
\hline \multicolumn{5}{|c|}{ Oil seeds* } \\
\hline 1 & Linseed & Linum usitatissimum & $16.55 \pm 1.4$ & $356.72 \pm 54.5$ \\
\hline 2 & Mustard (red) & Bassica nigra & $28.80 \pm 1.7$ & $20.9 \pm 2.5$ \\
\hline 3 & Mustard (yellow) & Bassica alba & $26.93 \pm 1.1$ & $20.0 \pm 2.2$ \\
\hline 4 & Sesame (Black) & Sesamum indicum & $17.71 \pm 1.4$ & $8.36 \pm 2.4$ \\
\hline 5 & Sesame (Brown) & Sesamum indicum & $15.92 \pm 0.9$ & $8.40 \pm 2.4$ \\
\hline \multicolumn{3}{|c|}{ Number of sample above $75^{\text {th }}$ quartile } & 5 & 1 \\
\hline \multicolumn{3}{|c|}{ Range } & $15.92-28.80$ & $8.36-356.72$ \\
\hline
\end{tabular}




\begin{tabular}{|l|l|l|l|l|}
\hline 1 & Black gram & Vigna mungo & $13.67 \pm 1.9$ & $11.85 \pm 1.8$ \\
\hline 2 & Green gram & Vigna radiata & $8.57 \pm 1.1$ & ND \\
\hline 3 & Grass pea & Lathyrus sativus & $7.52 \pm 0.6$ & $8.21 \pm 1.1$ \\
\hline 4 & Lens culinaris & $5.93 \pm 0.3$ & ND \\
\hline 5 & Lentil & Cicer arietinum & $7.45 \pm 0.5$ & ND \\
\hline Number of sample above $75^{\text {th }}$ quartile & 0 & 0 \\
\hline \multicolumn{2}{|l|}{ Range } & & $7.45-13.67$ & $8.21-11.85$ \\
\hline Cereals* & & & \\
\hline 1 & Porso millet & Panicum miliaceum & $4.87 \pm 0.6$ & $617.5 \pm 80.3$ \\
\hline
\end{tabular}

*Results are presented per gram of dry weight; ND: Not detectable

Determination of phenolic contents was followed by screening the $\mathrm{AC}$ of the test samples using the in vitro AC method of Brand-Williams. This method is also known as DPPH Radical Scavenging Assay, since it uses a stable commercial free radicle, diphenylpicrylhydrazyl radical, to be reduced by the phenolic compounds present in the sample extract. AC presented as DPPHRSA explicit that amount of DPPH free radical reduced or scavenged by the test material; hence the larger the value of AC greater potential to neutralize the free radicals produced in body. The highest AC among the analyzed foods was found in green teas, $2432.8 \mu \mathrm{mol} \mathrm{TE} / \mathrm{g} \mathrm{EP}$, and the lowest in Burmese grape, $0.11 \mu \mathrm{mol} \mathrm{TE} / \mathrm{g}$ EP. Like the TPC, AC of the analyzed foods demonstrated large variations, between and within some groups. However, AC within food groups varied in greater extent than the TPC, except for vegetables and pulses. The highest variation was found in teas, around $1163 \mu \mathrm{mol} \mathrm{TE} / \mathrm{g}$ EP, followed by oilseeds, fruits, and spices. The quartile of $\mathrm{AC}$ was $0.81,8.28$, and $39.07 \mu \mathrm{mol} \mathrm{TE} / \mathrm{g}$ EP and the number of foods above the 3rd quartile was $6,4,3,1$, and 0 in spices, tea, vegetables and oilseeds, and pulses respectively. Though teas showed maximum levels for both TPC and AC, the values for tea obtained from dry tea leaves which have very low moisture content than the prepared tea. Considering this fact, the values of the tea samples were recalculated for the prepared tea and found to possess both TPC and $\mathrm{AC}$ less than one tenth compared to the dry tea leaves. Interestingly, after this adjustment only prepared green tea have the highest TPC $(189.28 \mathrm{mg} / \mathrm{g})$ and AC $(196.07 \mu \mathrm{mol} \mathrm{TE} / \mathrm{g})$ amid the all analyzed foods and emblic became second most potent candidate.

\section{In vitro functionality: anti-inflammatory on $\mathbf{J 7 7 4 A . 1}$ cell line}

Functional potentiality of the food samples $(n=41)$ was screened using cell model for antiinflammatory activity. To measure the anti-inflammatory activity of the test samples, LPSinduced TNF- $\alpha$, a pro inflammatory cytokine, was produced in mouse macrophage, J774A cell; hence producing first phage of pathogen-induced inflammation in cell line. Though the inflammation is considered as an adaptive response to any detrimental stimuli, such as infection, tissue injury, and other noxious conditions threating the cell homeostasis, it is required to be least persevering to restore the normal cellular functions [33-34]. Thus, the potentiality of the samples measured by the percent inhibition of TNF- $\alpha$ production implies the restoration of normal cellular function.

Preliminary screening revealed that among 41 analyzed indigenous foods of Bangladesh, only 14 foods, exhibited inhibition above 70\% (data not shown), hence identified as potent candidates for dose response assay. Lactate dehydrogenase cytotoxicity assay was carried out to 
ascertain these inhibitions are not due to cytotoxicity. The dose response of the foods extracts were assayed using three different concentrations, $40,10,3$ and $1 \mu \mathrm{g} / \mathrm{mL}$, unlike the screening assay which used only $40 \mu \mathrm{g} / \mathrm{mL}$ of sample extract. The dose response assay confirmed 8 foods including two spices (radhuni and sweet fennel), two different tea samples (green tea and organic tea), black sesame, yellow mustard, green gram and lentil to have inhibitory effect on TNF- $\alpha$ production (Figure 1).

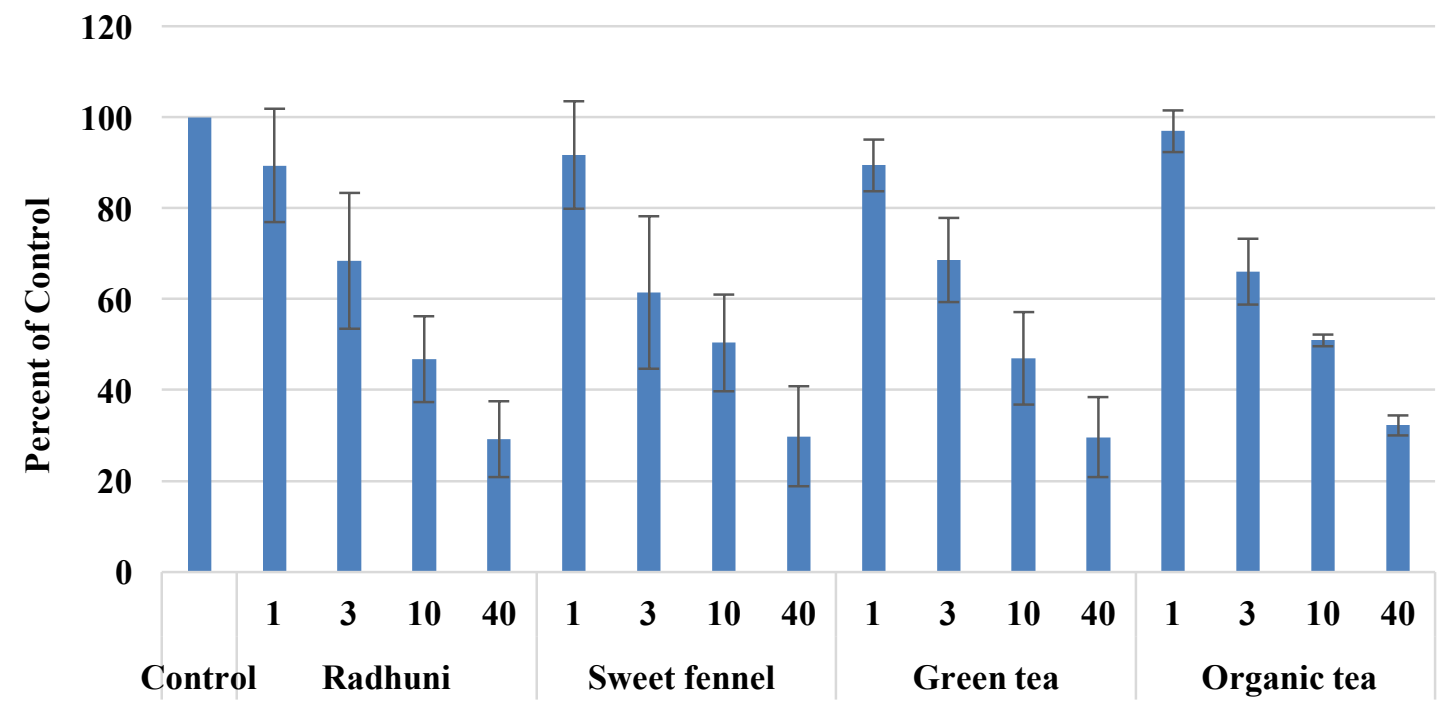

Concentration of the samples $(\mu \mathrm{g} / \mathrm{ml})$

(a)

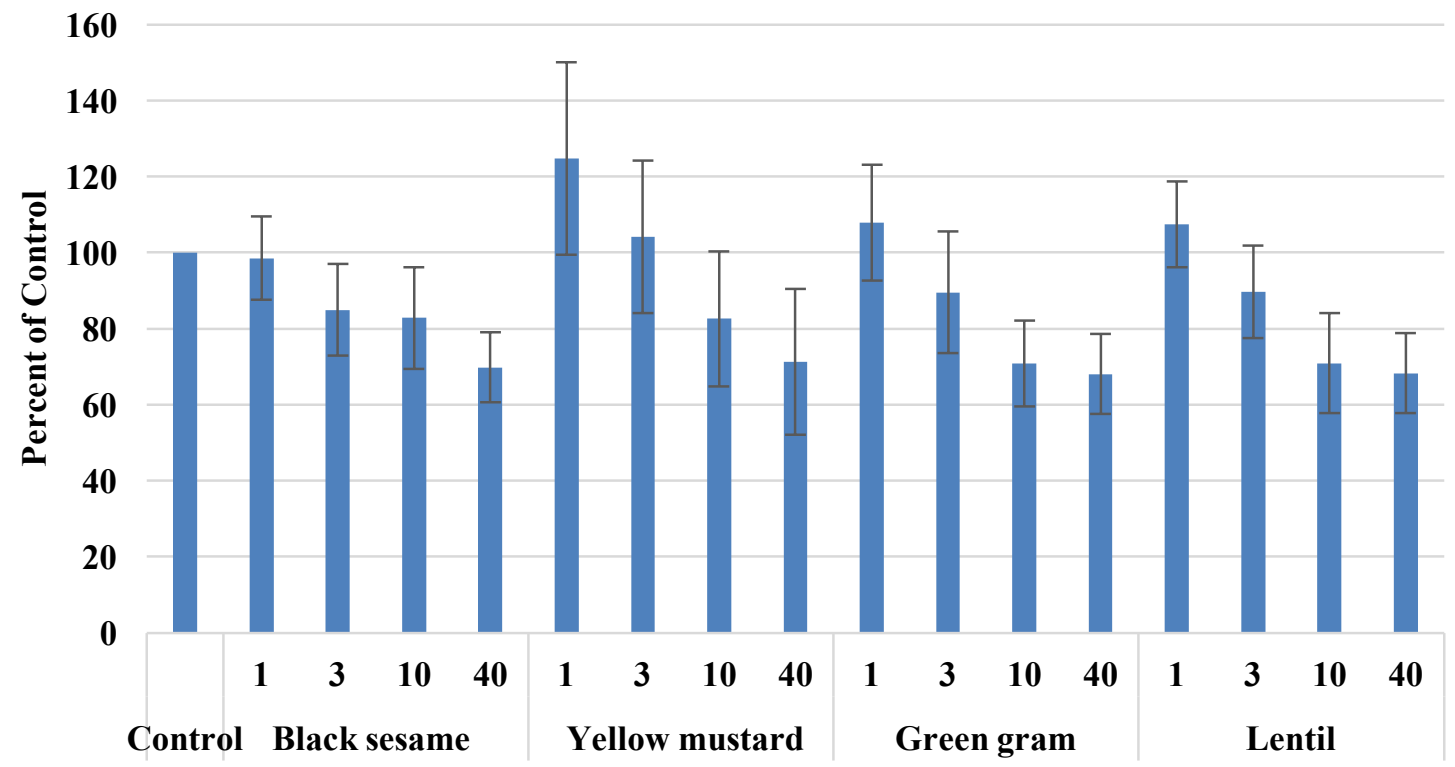

Concentration of the samples $(\mu \mathrm{g} / \mathrm{ml})$

(b)

Figure 1: Positive dose response of sample extracts [(a): Radhuni, Sweet fennel, Green tea, and Organic tea; (b) Black sesame, Yellow mustard, Green gram, and Lentil] on the inhibition of LPS stimulated TNF- $\alpha$ production of J774.a cells. 
All of the eight food samples, including the two spices (radhuni and sweet fennel), green tea, organic tea, black sesame, yellow mustard, green gram and lentil extracts demonstrated antiinflammatory activity against the LPS-induced TNF- $\alpha$ production. With increasing concentration of the sample extracts they reduced the produced concentration of TNF- $\alpha$ (Figure 1).

The polyphenols profile of black tea (Camellia sinensis) includes theaflavins, theaflavin 3O-gallate, theaflavin 30-O-gallate, theaflavin 3,30-O-gallate, epigallocatechin gallate, epicatechin gallate, catechins, 2-quercetin glycosides, quinic acid, gallic acid and caffeine and inhibits pancreatic lipase [35]. Presence of bioactive compounds in green tea and their health beneficial role are well documented and well accepted as health drink, which helps to reduce metabolic syndrome and some cancer risk, bone mineral density, fibrosis and neuronal degeneration [36]. Most prominent phenol of green tea, catechins (g/day) decreased the body weight of overweight men, without affecting blood pressure or metabolic function biomarkers [37]. Recent research has reported that the sesame seed contains sesamin, sesamolin and sesamol, which are all important antioxidant components in sesame seed oil [38].

\section{In vivo functional potentiality: anti-inflammatory and analgesic effects}

The functional potentiality of the assayed samples was confirmed using an animal model. Two in vivo methods, carrageenan-induced rat paw edema and acetic acid-induced writhing response in mice, were used to confirm the beneficiary effects of 4 (black sesame, lentil, green gram, and yellow mustard) out of 8 samples as mentioned in the previous section.

\section{Mouse writhing test}

Among the different algogenic agents stimulated within the pain-state experimental model, acetic acid induced writhing response in mice; this has drawn significant attention, due to its similarities to clinical pain occurred in inflammation. [39]. The intraperitoneal administration of acetic acid that irritate serous membranes elicits a stereotyped behavior in the mice, which is characterized by abdominal contractions, an arching of back, extension of hind limbs and contraction of abdominal musculature known as writhing. [40]. Analgesic activity of the test compound is inferred by the decrease in the frequency of writhing in the mice samples. Writhing is a manifestation of the intense pain induced by acetic acid via nociceptors. The signals transmitted to central nervous system in response to pain due to irritation, cause release of free arachidonic acid from tissue phospholipid via cyclooxygenase and prostaglandin biosynthesis. The release of these mediators increases the sensitivity of nociceptors, which eventually causes inflammatory pain to mice [41]. Thus, the analgesic activity of the test materials can be inferred from decrease in the frequency of writhing caused by restriction of prostaglandin synthesis, an anti-nociceptive activity.

The present study assesses the reduction of writhing caused by sesame black, lentil, green gram, and mustard yellow after administration of $0.6 \%$ acetic acid in mice intraperitoneally. Table 2 presents the mean number of writhing in treatment mice along with control and reference drug (diclofenac sodium) with their corresponding inhibition of agony compared to control. As Table 2 presents, the frequency of writhing is lowest in treatment mice receiving oral doses (200 $\mathrm{mg} / \mathrm{kg}$ p.o) of black sesame $(14.7 \pm 1.52)$ and yellow mustard $(14.7 \pm 1.14)$ extract amid all

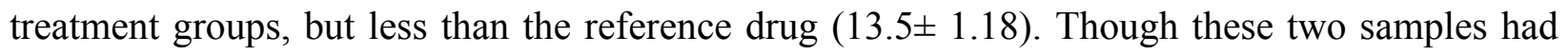


higher frequency of writhing than the reference, they had significantly decreased $(p<0.05)$ the number of writhing compared to the control with the percentage of inhibition being 27.26 and 27.27, respectively. The extracts of black sesame and yellow mustard had also shown analgesic at doses of $100 \mathrm{mg} / \mathrm{kg}$, p.o., but not at significant levels. Similarly, the DMSOW extract of lentil and green gram at any doses (100 and $200 \mathrm{mg} / \mathrm{kg}$, p.o.) did not significantly decrease the number of writhing induced by $0.6 \%$ acetic acid in mice (Table 2 ).

Table 2: Analgesic activity of Black sesame, Lentil, Green gram and Yellow mustard on $0.6 \%$ acetic acid-induced writhing in mice.

\begin{tabular}{lccc}
\hline Group & Dose (mg/kg, p.o.) & Number of $_{\text {writhings }}{ }^{\mathbf{2}}$ & \% inhibition \\
\hline Control & -- & $20.17 \pm 1.49$ & -- \\
Diclofenac sodium & 50 & $13.5 \pm 1.17^{* *}$ & 33.06 \\
Sesame (black) & 200 & $14.67 \pm 1.52^{*}$ & 27.27 \\
Sesame (black) & 100 & $18.17 \pm 1.22$ & 9.92 \\
Lentil & 200 & $17.67 \pm 1.70$ & 12.40 \\
Lentil & 100 & $18.17 \pm 1.45$ & 9.92 \\
Green gram & 200 & $18.34 \pm 1.09$ & 9.09 \\
Green gram & 100 & $19.17 \pm 1.33$ & 4.96 \\
Mustard (yellow) & 200 & $14.67 \pm 1.15^{*}$ & 27.27 \\
Mustard (yellow) & 100 & $17.33 \pm 1.12$ & 14.05 \\
\hline
\end{tabular}

${ }^{\mathrm{a}}$ Values are presented as mean \pm S.E.M $(\mathrm{n}=6)$

$* p<0.05$ compared with the control group (Dunnett's test)

${ }^{*} p<0.001$ compared with the control group (Dunnett's test)

\section{Carrageenan induced rat paw edema}

Carrageenan induced rat paw edema model, frequently used to assess anti-inflammatory effects as an in vivo model, produces cardinal signs of acute inflammation after subcutaneous injection of carrageenan. Signs like edema, hyperalgesia, and erythema result from the production of proinflammatory agent, bradykinin, histamine, tachykinins, reactive oxygen, and nitrogen species etc. In response to carrageenan injection, neutrophils migrate to the site of inflammation and generate pro-inflammatory agents which causes formation of edema in a biphasic process. In first phase of post-carrageenan injection, between 0 and $2 \mathrm{~h}$, there is a release of histamine and serotonin attributing the increase vascular permeability. Second phase is characterized by production and release of bradykinin, protease, prostaglandins and lysosome. The inflammatory response is found in literature to maximum at 5 hours and after that modulated by the inhibitory molecules within the inflammatory cascade [42]. To assess the anti-inflammatory effects of test materials, the reduction in paw size is measured within the inflammatory response periods $0-5 \mathrm{~h}$ and compared to the controls for quantification of inhibition and to reference drug for extent effectiveness. In the present study, volume of edematous paws were measured in every hour of post-carrageenan injection and found to increase progressively to reach the maximal intensity in $4 \mathrm{~h}$. Figure 2 presents the size of the paws of treatment group, rat fed on DMSOW extract of 4 samples, compared to that of control and the percentage of inhibition as the measure of antiinflammatory activity. 
3

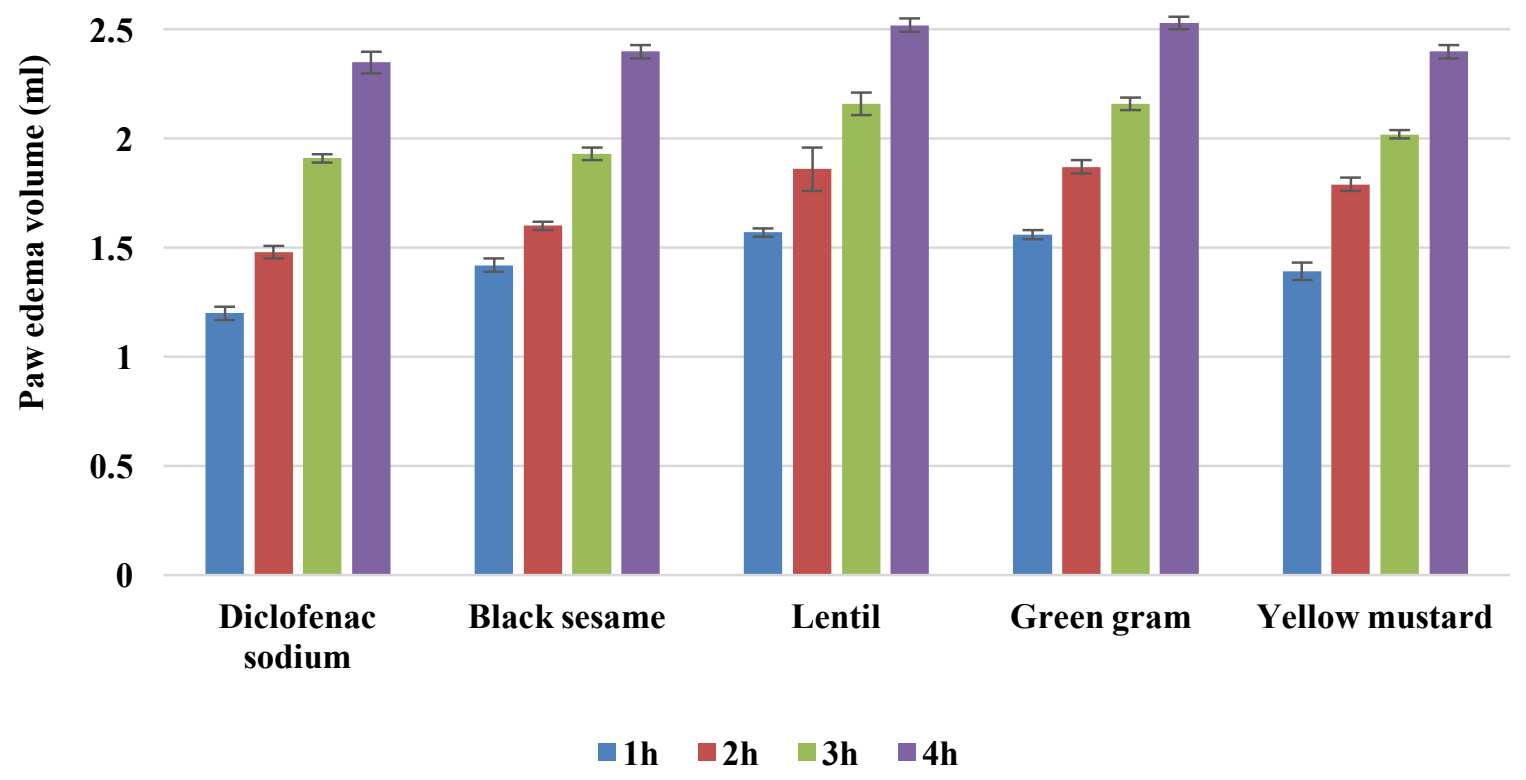

(a)

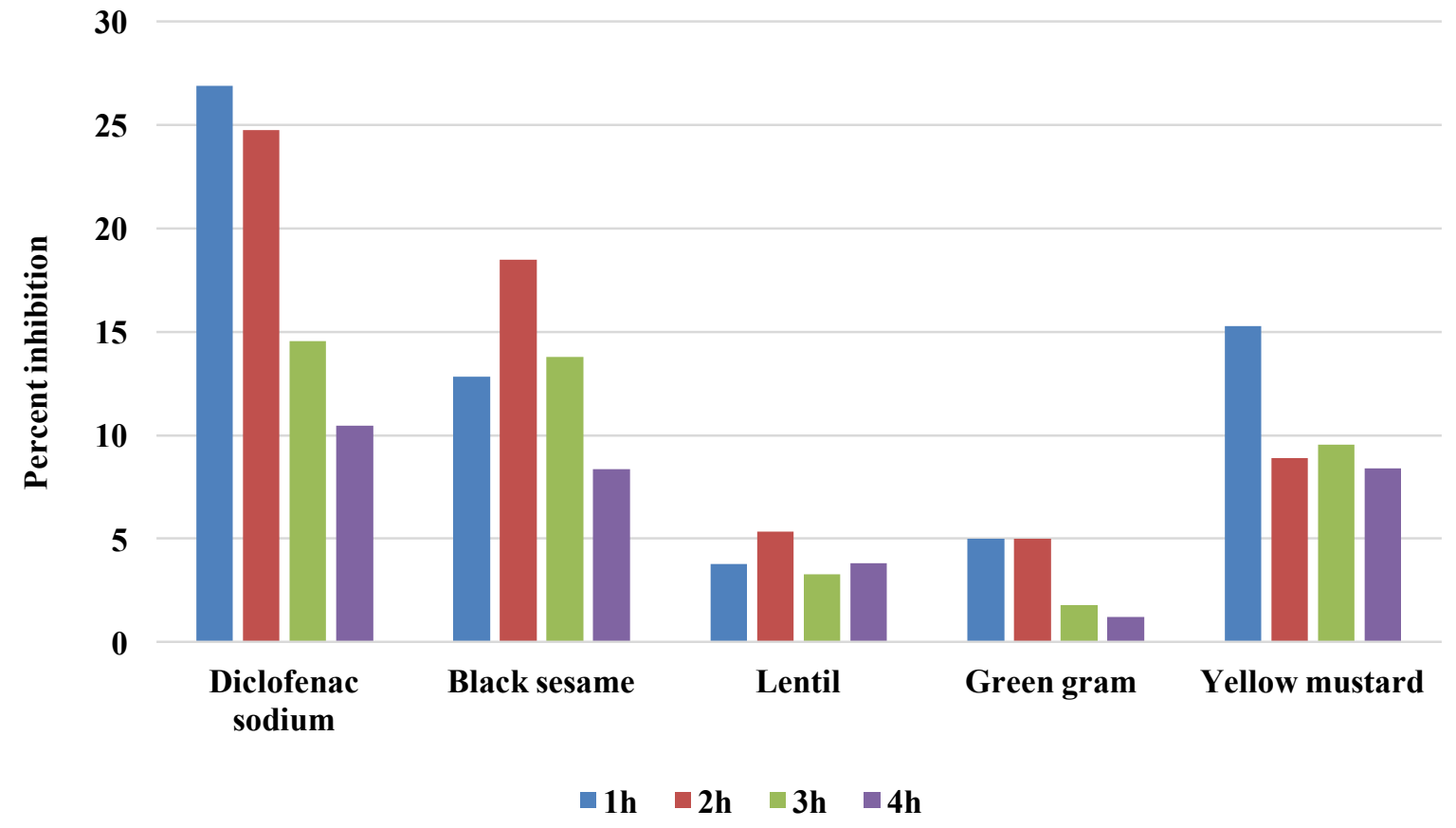

(b)

Figure 2: Effect of DMSOW extract of black sesame, lentil, green gram, and yellow mustard on carrageenan-induced paw edema in rats at $200 \mathrm{mg} / \mathrm{kg}$, p.o.. (a) shows change in paw edema volume $(\mathrm{ml})$ at $1,2,3$ and $4 \mathrm{~h}$ (values are presented as mean \pm S.E.M. $(\mathrm{n}=6)$ ). (b) shows percent inhibition of the carrageenan induced paw edema volume at 1,2,3 and $4 \mathrm{~h}$. 
As shown in the figure 2, the swelling increased progressively to a maximum volume of $2.62 \pm 0.09 \mathrm{ml}$ at $4 \mathrm{~h}$ after the carrageenan injection. Significant reduction of paw edema volume was observed in the rat treated with diclofenac sodium $(50 \mathrm{mg} / \mathrm{kg}$, p.o.) with the percentage of inhibition of $26.89,24.76,14.54$, and 10.45 at $1,2,3$, and $4 \mathrm{~h}$, respectively compared to the control. Only DMSOW extract of black sesame and yellow mustard ( $200 \mathrm{mg} / \mathrm{kg}$, p.o.) produced a significant $(\mathrm{p}<0.05)$ and dose-dependent inhibition of the paw edema induced by carrageenan when compared with control. Black sesame and yellow mustard at the doses $200 \mathrm{mg} / \mathrm{kg}$ caused $18.68 \%(\mathrm{p}<0.05)$ and $15.66 \%(\mathrm{p}<0.05)$ inhibition against carrageenan induced paw edema noted at $1 \mathrm{~h}$ and $2 \mathrm{~h}$ of carrageenan challenge, respectively (Figure 2). The inhibition of rat paw edema of black sesame at the dose of $200 \mathrm{mg} / \mathrm{kg}$, p.o. at 1, 2, 3 and $4 \mathrm{~h}$ was $12.835,18.49,13.79$ and 8.35 percent, respectively while the yellow mustard at the dose of $200 \mathrm{mg} / \mathrm{kg}$, p.o. decreased the rat paw edema at $1,2,3$ and $4 \mathrm{~h}$ by $15.27,8.90,9.54$ and 8.40 percent, respectively when compared to the control. The DMSOW extract of black sesame and yellow mustard at dose of $100 \mathrm{mg} / \mathrm{kg}$, p.o., and lentil and green gram at any doses $(100$ and $200 \mathrm{mg} / \mathrm{kg}$, p.o.) did not significantly inhibited carrageenan-induced rat paw edema in rats when compared with control (Figure 2).

The evidence from the present study implies that the significant analgesic and antiinflammatory effect of the extracts of black sesame and yellow mustard may be due to the modulatory principles acting with the prostaglandin alley which also corroborates previous findings that sesame oil displays significant analgesic as well as anti-inflammatory activity [4344]. It is likely that the effects are due to lignan constituents that are known to have these analgesic and anti-inflammatory properties. According to chemical composition, the lignin in sesame seed oil can be categorized into two types, i.e. inherent lignans (sesamin, sesamolin) and lignans mainly formed during the oil production process (sesamol, sesamolinol, etc.) [38]. More detail studies reported that sesamin and sesamolin have shown antioxidant [45], antiproliferative [46-47], antihypertensive [48-49], and neuroprotective activities [50], as well as lowering cholesterol levels [51] and increasing hepatic fatty acid oxidation enzymes [52].

\section{CONCLUSION}

Having recognized the increasing attention polyphenolic compounds are gaining for their noticeable antioxidant property, this article reports the total polyphenols content of 70 food items comprising different food groups of Bangladesh. The study also revealed the functional potential of selected food items like 2,2-diphenyl-1-picrylhydrazyl radical scavenging activity, effect on pro-inflammatory cytokine TNF- $\alpha$ production using J774A.1 cells, inhibition of carrageenan induced edema in the right hind paw of rats, and reduction in the number of writhes induced by injecting acetic acid in rats (in vivo analgesic potential). This study found commonly consumed food items representing different food groups of Bangladesh to contain diverse range of polyphenols and antioxidant capacities. Spices, oilseeds, and teas demonstrated high concentrations of TPC among the analyzed foods, while spices and teas also exhibited noteworthy antioxidant activity. Black sesame and yellow mustard have been shown to demonstrate anti-inflammatory and analgesic effects in a dose dependent manner. The findings of this study can be used to promote polyphenols rich foods through dietary guidelines and facilitate epidemiological research investigating diet-disease relationships. However, further 
research needs to be carried out to investigate the mechanistic pathway with the mediating biomarkers through which these food extracts exert their functionality.

\section{Conflict of interest}

The authors declare no conflict of interest

\section{REFERENCES}

1. FAO, IFAD and WFP. The State of Food Insecurity in the World 2015: Meeting the 2015 international hunger targets: taking stock of uneven progress. Rome, FAO; 2015.

2. National Institute of Population Research and Training (NIPORT), Mitra and Associates, and ICF International. Bangladesh Demographic and Health Survey 2014. Dhaka, Bangladesh, and Rockville, Maryland, USA: NIPORT, Mitra and Associates, and ICF International; 2016.

3. International Centre for Diarrhoeal Disease Research, Bangladesh (icddr,b), UNICEF, Bangladesh, Global Alliance for Improved Nutrition (GAIN) and the Institute of Public Health and Nutrition (IPHN). National Micronutrients Status Survey. Dhaka, Bangladesh; 2011-12.

4. Food Planning and Monitoring Unit (FPMU) and FAO. National Food Policy Plan of Action and Country Investment Plan: Monitoring Report 2015. Dhaka, Bangladesh; 2015.

5. Ministry of Health \& Family Welfare (MoH\&FW), Bangladesh Society of Medicine, N.C.D and World Health Organization (WHO). Non-Communicable Disease Risk Factor Survey Bangladesh 2010. Bangladesh, WHO; 2010.

6. Lozano R, Naghavi M, Foreman K, Lim S, Shibuya K, Aboyans V, Abraham J, Adair T, Aggarwal R, Ahn SY, AlMazroa MA: Global and regional mortality from 235 causes of death for 20 age groups in 1990 and 2010: a systematic analysis for the Global Burden of Disease Study 2010. The Lancet 2013, 380(9859):2095-128.

7. Raiten DJ, Ashour FA, Ross AC, Meydani SN, Dawson HD, Stephensen CB, Brabin BJ, Suchdev PS, Van Ommen B: Inflammation and nutritional science for programs/policies and interpretation of research evidence (INSPIRE). The Journal of nutrition 2015, 145(5):1039S-1108S.

8. López-Varela S, González-Gross M, Marcos A: Functional foods and the immune system: A review. Eur J Clin Nutr 2002, 56(suppl 3):S29-33.

9. Calder PC, Albers R, Antoine JM, Blum S, Bourdet-Sicard R, Ferns GA, Folkerts G, Friedmann PS, Frost GS, Guarner F, Løvik M: Inflammatory disease processes and interactions with nutrition. British Journal of Nutrition 2009, 101(suppl S1):1-45.

10. Khansari N, Shakiba Y, Mahmoudi M: Chronic inflammation and oxidative stress as a major cause of age-related diseases and cancer. Recent patents on inflammation \& allergy drug discovery 2009, 3(1):73-80.

11. Pham-Huy LA, He H, Pham-Huy C: Free radicals, antioxidants in disease and health. Int J Biomed Sci 2008, 4(2):89-96. 
12. Fusco D, Colloca G, Lo Monaco MR, Cesari M: Effects of antioxidant supplementation on the aging process. Clin Interv Aging 2007, 2:377-387.

13. Nitta H, Kinoyama M, Watanabe A, Shirao K, et al: Effects of nutritional supplementation with antioxidant vitamins and minerals and fish oil on antioxidant status and psychosocial stress in smokers: an open trial. Clin Exp Med 2007, 7:179-183.

14. Baedia A, Tleyjeh IM, Cerhan JR, Sood AK, et al: Efficacy of antioxidant supplementation in reducing primary cancer incidence and mortality: systematic review and meta-analysis. Mayo Clin. Proc 2008, 83:23-34.

15. Kannappan S, Anuradha CV: Insulin sensitizing actions of fenugreek seed polyphenols, quercetin and metformin in a rat model. Indian J Med Res 2009, 129(4):401-408.

16. Serafini M, Bellocco R, Wolk A, Ekström AM: Total antioxidant potential of fruit and vegetables and risk of gastric cancer. Gastroenterology 2002, 123(4):985-91.

17. Hasan SR, Hossain MM, Akter R, Jamila M, Mazumder ME, Rahman S: DPPH free radical scavenging activity of some Bangladeshi medicinal plants. Journal of Medicinal plants research. 2009, 3(11):875-9.

18. Tukun AB, Shaheen N, Banu CP, Mohiduzzaman Md, Islam S, Begum M: Antioxidant capacity and total phenolic contents in hydrophilic extracts of selected Bangladeshi medicinal plants. Asian Pacific Journal of Tropical Biomedicine 2014, 4(9):703-708.

19. Hossain S, Shaheen N, Banu CP, Mohiduzzaman M: Total polyphenol content (TPC) and anti-oxidant activity of selected Tropical vegetables. Mal J Nutr 2011, 17(3):377383.

20. Mamun S, Shaheen N, Basak Tukun A, Mohiduzzaman M, Banu CP, Takano-Ishikawa Y: Hydrophilic Antioxidant Capacities and Total Phenol Content of Seasonal Fruits of Bangladesh. Mal J Nutr 2012, 18(3):355-362.

21. Shaheen N, Kurshed AAM, Karim KMR, Mohiduzzaman M, Banu CP, Begum M, Takano-Ishikawa Y: Total phenol content of different varieties of brinjal (Solanum melongena L.) and potato (Solanum tuberosum L.) growing in Bangladesh. Bangladesh J Bot 2013, 42(1):175-177.

22. Singlleton VL, Rossi JA. Colorimetry of total phenolics with phosphomolybdicphosphotungstic acid reagents. Am J Enol Vitic 1965, 16:144-158.

23. Brand-Williams W, Cuvelier ME, Berset C. Use of a free radical method to evaluate antioxidant activity. LWT-Food Sci Technol 1995, 28:25-30.

24. Tukun AB, Shaheen N, Banu CP, Mohiduzzaman M, Islam S, Begum M: Antioxidant capacity and total phenolic contents in hydrophilic extracts of selected Bangladeshi medicinal plants. Asian Pacific journal of tropical medicine 2014, 7 (Suppl 1):S568-73.

25. Herath HMT, IshikawaYT, Yamaki K: Inhibitory effect of some flavoniods on Tumor Necrosis Factor- $\alpha$ production in Lipopolysaccharide-stimulated mouse macrophage cell line J774.1. J Med Food 2003, 6 (4):365-370.

26. Winter CA, Risley EA, Nuss GW: Carrageenan induced edema in hind paw of the rat as an assay for anti-inflammatory drugs. Proc Soc Exp Biol Med 1962,111:544-7.

27. Yesilada E, Kupeli E: Berberis crataegina DC. root exhibits potent anti-inflammatory, analgesic and febrifuge effects in mice and rats. J Ethnopharmacol 2002,79:237-48. 
28. Koster R, Anderson M, De Beer EJ: Acetic acid for analgesic screening. Fed Proc 1959,18:412-6.

29. Whittle BA: The use of changes in capillary permeability in mice to distinguish between narcotic and non-narcotic analgesics. Br J Pharmacol Chemotherp 1964, 22:246-53.

30. Zakaria M, Islam M, Radhakrishnan R, Chen H, Kamil M, Al-Gifri A, Chan K, Al-Attas A: Anti-nociceptive and anti-inflammatory properties of Caralluma arabica. Journal of Ethnopharmacology 2001, 76:155-158.

31. Silva J, Abebe W, Sousa S, Duarte V, Machado M, Matos F: Analgesic and antiinflammatory effects of essential oils of Eucalyptus. Journal of ethnopharmacology 2003, 89:277-283.

32. Daayf F, Lattanzio V: Recent Advances in Polyphenol Research. Vol. 1. John Wiley \& Sons, 2008.

33. Ahmed AU: An overview of inflammation: mechanism and consequences. Frontiers in Biology 2011, 6(4):274-81.

34. D’Alessandro Tracy, Prasain J, Benton M R, Bottling N, Moore R, Darley-Usmar V, et al.: Polyphenols, inflammatory response and cancer prevention: Chlorination of isoflavones by human neutrophils. The Journal of Nutrition 2003, 133(11 Suppl 1):3773S-3774S.Al Mahmud Z, Emran TB, Qais N, Bachar SC, Sarker M, Uddin N, Muhammad M: Evaluation of analgesic, anti-inflammatory, thrombolytic and hepatoprotective activities of roots of Premna esculenta (Roxb). Journal of basic and clinical physiology and pharmacology 2016, 27(1):63-70.

35. Yuda N, Tanaka M, Suzuki M, Asano Y, Ochi H, Iwatsuki K: Polyphenols extracted from black tea (Camellia sinensis) residue by hot-compressed water and their inhibitory effect on pancreatic lipase in vitro. J Food Sci 2012, 77(Suppl 12):H254-61.

36. Cabrera C, Artacho R, Giménez R: Beneficial effects of green tea-a review. JACN 2006, 25(2):79-99.

37. Brown AL, Lane J, Holyoak C, Nicol B, Mayes AE, Dadd T: Health effects of green tea catechins in overweight and obese men: a randomised controlled cross-over trial. British Journal of Nutrition 2011, 106(12):1880e1889.

38. Wan $\mathrm{Y}, \mathrm{Li} \mathrm{H}, \mathrm{Fu} \mathrm{G}$, Chen $\mathrm{X}$, Chen F, Xie M: The relationship of antioxidant components and antioxidant activity of sesame seed oil. Journal of the Science of Food and Agriculture 2015, 95(13):2571-8.

39. Parle M, Yadav M: Laboratory models for screening analgesics. Int Res J Pharm 2013; 4:15-9.

40. Dannerman PJ: Monitoring of analgesia. In: Anesthesia and Analgesia in Laboratory Animals. $1^{\text {st }}$ edition. Edited by Kohn DK, Sally K, Wixson B, White WJ, John G. USA: Academic Press; 1977:83-99.

41. Ullah HA, Zaman S, Juhara F, Akter L, Tareq SM, Masum EH, Bhattacharjee R: Evaluation of antinociceptive, in-vivo \& in-vitro anti-inflammatory activity of ethanolic extract of Curcuma zedoaria rhizome. BMC complementary and alternative medicine 2014, 14(1):1.

42. Al Mahmud Z, Emran TB, Qais N, Bachar SC, Sarker M, Uddin N, Muhammad M: Evaluation of analgesic, anti-inflammatory, thrombolytic and hepatoprotective activities 
of roots of Premna esculenta (Roxb). Journal of basic and clinical physiology and pharmacology 2016, 27(1):63-70.

43. Monteiro ÉMH, Chibli LA, Yamamoto CH, Pereira MCS, Vilela FMP, Rodarte MP, De Oliveira Pinto MA, Do Amaral MDPH, Silvério MS, De Matos Araújo A LS: Antinociceptive and Anti-Inflammatory Activities of the Sesame Oil and Sesamin. Nutrients 2014, 6:1931.

44. Saleem TM, Basha SD, Mahesh G, Rani PS, Kumar NS, Chetty C: Analgesic, antipyretic and anti-inflammatory activity of dietary sesame oil in experimental animal models. Pharmacologia 2011, 2:172-7.

45. Suja KP, Jayalekshmy A, Arumughan C: Free radical scavenging behavior of antioxidant compounds of sesame (Sesamum indicum L.) in DPPH system. Journal of Agricultural and Food Chemistry 2004, 52:912-915.

46. Yokota T, Matsuzaki Y, Koyama M, Hitomi T, Kawanaka M, Enoki-Konishi M, Okuyama Y, Takayasu J, Nishino H, Nishikawa A: Sesamin, a lignan of sesame, down-regulates cyclin D1 protein expression in human tumor cells. Cancer science 2007, 98:1447-1453.

47. Hemalatha S, Rao M: Sesame lignans enhance antioxidant activity of vitamin $\mathrm{E}$ in lipid peroxidation systems. Molecular and cellular biochemistry 2004, 262:195.

48. Lee C, Chen P, Lin S, Tsai S, Wang B, Chen W, Tsai C, Shyu K: Sesamin induces nitric oxide and decreases endothelin-1 production in HUVECs: possible implications for its antihypertensive effect. Journal of hypertension 2004, 22:2329.

49. Nakano D, Kurumazuka D, Nagai Y, Nishiyama A, Kiso Y, Matsumura Y: Dietary sesamin suppresses aortic NADPH oxidase in DOCA salt hypertensive rats. Clinical and Experimental Pharmacology and Physiology 2008, 35:324-326.

50. Cheng FC, Jinn TR, Hou R, Tzen J T: Neuroprotective effects of sesamin and sesamolin on gerbil brain in cerebral ischemia. Int J Biomed Sci 2006, 2:284-8.

51. Visavadiya NP, Narasimhacharya A: Sesame as a hypocholesteraemic and antioxidant dietary component. Food and Chemical Toxicology 2008, 46:1889-1895.

52. Ashakumary L, Rouyer I, Takahashi Y, Ide T, Fukuda N, Aoyama T, Hashimoto T, Mizugaki M, Sugano M: Sesamin, a sesame lignan, is a potent inducer of hepatic fatty acid oxidation in the rat. Metabolism 1999, 48:1303-1313. 